\title{
Helping students demonstrate mastery of doctoral threshold concepts
}

\author{
Gina Wisker
}

Margaret Kiley

Research into the characteristics of successful PhD theses (See for example Bourke, Hattie, \& Anderson, 2004; Holbrook \& Bourke, 2004; Kiley \& Mullins, 2004; Lovitts, 2007; Mullins \& Kiley, 2002) suggests that examiners expect to see evidence of a variety of relatively abstract rather daunting achievements and skills. We propose that this might be because satisfactory completion of a $\mathrm{PhD}$ indicates both a contribution to knowledge as well as providing evidence of conceptual, critical and creative research and articulation. This evidence demonstrates a range of related disciplinary or inter-disciplinary understandings and skills at the doctoral level. Terms such as 'conceptual framework', 'critical perspective', 'contribution to knowledge' and their abstract indicators are examples of those rather elusive aims in doctoral research. For candidates to be able to bring such achievements into their writing, focused, accessible and timely feedback from supervisors is essential.

Supervisory feedback, both oral and written, offers specific advice, based in the broader understanding and recognition of what those rather abstract terms indicate in practice, and tailored to students' own writing positions and production. In the light of the importance of the written contribution, which is what examiners see, and which eventually leads to publications, we suggest that research into Threshold Concepts at the doctoral level provides a particularly helpful framework for feedback on students' written expression and articulation of their research practice and achievement.

Threshold Concepts (Meyer \& Land, 2005/2006a/2006b) are those concepts that are critical to a learners' understanding of a discipline. The Threshold Concepts understanding of learning has been applied to 'learning to be a researcher'; theory, and argument have been identified as concepts that often challenge learners (Kiley, 2009). Understanding these concepts is seen as being critical to successfully crossing the various conceptual thresholds at stages in the research journey, and to becoming an effective researcher (Kiley \& Wisker, 2009; Wisker, Kiley, \& Aiston, 2006). Therefore, one of our roles as supervisors is to find and develop the feedback language to bring these essential threshold concepts and conceptual threshold crossings into doctoral students' view, so they can recognise and embark on the journey to demonstrate them in the written thesis.

Every doctoral student is different, every project is different, and each has its own nuances in relation to questions, problems, processes, research, modes of articulation of the question and the achievement of research outcomes and processes. Ensuring clear and appropriate feedback on conceptual levels of work is the most sensitive, and as supervisors we have to 
find ways to express the abstract, the complexly conceptual and help make it accessible, through our feedback so that candidates can own and translate what it means into their own work and expression.

\section{Threshold concepts and conceptual thresholds in doctoral learning and expression}

There are a number of characteristics of a Threshold Concept (Meyer \& Land, 2006b), for example, boundedness, irreversibility, and transformation, which have been applied to a number of concepts that supervisors, when interviewed, consider are the most challenging for their own students. Threshold concepts related to learning to be a researcher include: argument/thesis, theory, framework, knowledge creation, analysis, research paradigm, creativity, scholarly writing and doctorateness (Humphrey \& Simpson, 2012; Kiley, 2009, 2010; Trafford \& Leshem, 2009). Each of these concepts requires the learner to engage deeply and conceptually. Once fully understood and the conceptual threshold crossed, the learner is then able to demonstrate this understanding through a range of behaviours, skills and abilities. These are generally the behaviours, skills and abilities we expect from an effective researcher in relation to their research work, and their articulation of it.

Additionally, it is helpful to be aware of some of the behaviours that candidates exhibit while coming to terms with these concepts. One common behaviour is mimicry (Wisker \& SavinBaden, 2009; Bhabha, H., 1994), where learners use terms and phrases that they understand to be critical in their discipline, but of which they have little or no understanding. Many successful researchers report engaging in mimicry as $\mathrm{PhD}$ candidates themselves, until one day they actually understood what they had previous been pretending to understand and talk about.

Meyer and Land (2006b) also suggest that another feature of grappling with understanding a Threshold Concept is 'stuckness'. Research at the doctoral level (Kiley, 2014) suggests that many candidates feel as if they are "going round in circles", or "knocking their head against a brick wall" when they are in a stuck place. This is often when candidates consider withdrawing from their programme and where the idea of 'nudging' them across threshold concepts can be very helpful when giving feedback. Such nudging might include offering advice about overcoming writing blocks and fostering discussions leading to fuller, clearer understanding (Wisker \& Savin-Baden, 2009; Wisker, 2014), and bring about breakthroughs in writing.

\section{Manifestation in thesis writing}

According to researchers across a range of different countries, examiners generally agree on similar qualities in what they would describe as a 'good' thesis (Denicolo, 2003; Holbrook, Bourke, Lovat, \& Dally, 2004; Lovitts, 2007; Mullins \& Kiley, 2002). Likewise, as Mullins 
and Kiley (2002: 378-9) found from interviews with supervisors, there are also commonlyshared views about the characteristics of a poor thesis:

- lack of coherence;

- lack of understanding of the theory;

- lack of confidence;

- $\quad$ researching the wrong problem;

- mixed or confused theoretical and methodological perspectives;

- $\quad$ work that is not original;

- not being able to explain at the end [...] what had actually been argued in the thesis.

These characteristics relate closely to the Threshold Concepts outlined above. For example, from their written and oral reports, examiners frequently talk about the need for a coherent argument, that is, telling a story that is supported by evidence/data. This, we argue, is reflected in the Threshold Concept of argument/thesis. A lack of understanding of theory relates closely to the Threshold Concept of theory. Holbrook, Bourke, and Fairbairn (2015) note that examiners' reports stressed the following in relation to theory: "“accuracy and completeness', 'grasp', 'alignment', 'coherence and consistency', 'treatment of findings and discussion', and 'dimensions of contribution'” (75). However, they argue that examiners' comments on theory vary by discipline, with a far higher percentage in disciplines such as Education and Humanities and Social Sciences, more generally followed by Science and specifically by Health (79). Examiners don't always comments on theory but candidates who "achieve distillation in communication, thinking, and maturity of insight about theory are recognised by examiners as particularly high achievers in that area” (Holbrook, Bourke \& Fairbairn, 2015: 84).

Another comment made frequently in reports concerns the (lack of) evidence of critical analysis, reflecting the Threshold Concept of analysis. Unsurprisingly, most reports highlight contributions to knowledge. For candidates, understanding that their research should make an original contribution to knowledge reflects the Threshold Concept of knowledge creation in learning to be a researcher. A scholarly approach to writing and presentation is another frequently mentioned criterion of a good thesis, matching the Threshold Concept of writing. Methodology/research design is another criterion commonly noted in examiners' reports and discussions, and links with the two Threshold Concepts of framework and paradigm.

A number of examiners make mention of the candidate who has taken a creative approach to their work. This use of the word creative is not specific to the creative arts, but more the candidate who tried for something outside the norm or tackled a risky project but didn't quite manage to meet the requirement. In this case the Threshold Concept of creativity comes into play. Finally, the scholarly nature of the writing in a thesis is generally one of the main 
criteria expected by institutions when sending theses examiners. Trafford and Leshem (2009) suggest that, when a research candidate can bring together all these various components of a doctorate, then the student has achieved "Doctorateness".

\section{Feedback and nudging}

In relation to threshold concepts' achievement and conceptual threshold crossings in doctoral work, Wisker et al. (2010) developed the notion of 'nudging': a set of focused, individually nuanced but persistent strategies to urge or prompt students into working at an increasingly more conceptual, critical and creative level-and expressing this in their work. Some of these practices are quite generic, some discipline-specific, and others target the specific stage of writing a student is at. They include

- offering models and explaining what they initiate in terms of thinking,

- engaging with questions of articulation,

- suggesting that students find models themselves,

- prompting and exemplifying ways in which students can engage with theories and concepts and take on any of these to underpin their questioning, research processes, research journeys and scrutiny and interpretation of data.

This feedback and nudging should also influence articulation of the doctorate as a whole in writing. Whereas a supervisory comment such 'you need to theorise' will convey little and is likely to waste time in terms of anxiety about its meaning, students can be guided, not by track changes, but by examples and suggestions and questions, linking words, rephrasing and integration of critical text with their own arguments and findings, as models to take through the rest of the piece of writing.

Some of the nudges are local and specific, some are open questions. For example, when urging theorisation, a comment such as: 'How does the idea of Baudrillard concerning space offer insights here?' nudges critical thinking in a specific form, and also sets up a pattern for ensuring students' integration of critical works with their own. Offering a perspective, even to the extent of sharing a quotation or a example of someone else's work where a theorist's perspective offers clarification, will enable greater insight and clearer expression. The point of good feedback is to engage thinking and dialogue, to enable and empower rather than to humiliate, confuse, give answers (except when correcting factual errors) or substitute the work of the supervisor for that of the student. Feedback engages student and supervisor in a creative critical dialogue of the work with the product being evidence of learning that will satisfy examiners' expectations.

Feedback, like any teaching and learning, is a dialogue between the supervisor, the student's understanding as expressed in their writing, and finally the examiners (and, if published, 
future readers). The supervisor offers a view of the specific actions needed in the written work to ensure clear expression, and enable readers to understand the student's achievements. Supervisors need to learn the language with which to give useful feedback to enhance students' precise articulation of their understanding. Feedback that is confusing, abrupt or generic is probably caused by just not having the words to engage. Our aim in giving feedback is specific guidance, engagement with specific needs at different stages, in terms of both the discipline and the writing. Good feedback is empowering when it nudges conceptualisation, then articulation. With good feedback, we are inducting students into the gradual use and ownership of appropriate expression, as they move through stages of mimicry to increasing confidence in their own 'voice', and articulate complex ideas and understandings. Their writing should showcase their achievements to best effect.

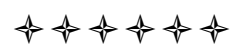




\section{Building bulwarks: Defence in thesis writing}

Susan Carter (University of Auckland, New Zealand)

The thesis stands amongst the most defensive of textual genres. Like many creatures, its survival rests on a convincing display of defence, because the primary reader is a rigorous examiner. That person, working beyond their day job, often in snatches, is charged with checking that institutional criteria of a masters or doctoral degree are met. As a fairly standard example, the Statute for the Degree of Doctor of Philosophy at the University of Auckland (2012) requires that the doctoral thesis

1. is an original contribution to knowledge or understanding in its field

2. meets internationally recognised standards for such work

3. demonstrates knowledge of the literature relevant to the subject and the field or fields to which the subject belongs, and the ability to exercise critical and analytical judgement of it

4. is satisfactory in its methodology, in the quality and coherence of its expression, and in its scholarly presentation and format

Students need to demonstrate in writing that they have met these criteria, attesting that they possess research skills for future independent work (as defined by the Research Council, n.d, for example). This need to demonstrate makes the thesis a highly prescribed genre (Carter, 2011). Supervisors can shore up their students' defences, since the criteria that guide examiners can also inform research students (Boulter \& Denicolo, 2002; Trafford \& Leshem, 2002/2008). Although examination is not an early concern, it can direct students' early earlystage thesis writing and their final revision before submission.

\section{Ensuring satisfactory choices}

As methodological decisions are made in the first few months of the doctorate, students should be encouraged to write down the rationale behind choices in clear formal language (e.g, why they rejected some methods, theories, delineated sample size etc.), in order to preempt examiner questions. Some choices will emerge from early supervision meetings: directly thereafter, students can be encouraged to write up their reasoning. Whatever they produce in these early stages is likely to find a place within the thesis as a means of demonstrating methodological soundness. Writing while choosing means reasoning won't be forgotten later, forfeiting patently clear defence. A confidence-booster for students is that this activity generates relatively easily written words, with the by-product of giving supervisors writing early on so they know what they are in for and can begin the feedback process.

Examiners warm to introductions that convey the student's motivations for the project (Carter, 2008)—fostering writing in the early phase makes it more likely that this first glow 
of enthusiasm will infuse the prose. Once students recognise the need to formally defend their research, they can begin to develop skills in packaging their thoughts for the convenience and pleasure of readers (Sword, 2009). Later, in the revision stages, supervisors can remind students to check whether they have documented the decision-making process clearly enough in the thesis. Such attention to detail can help ensure, when the thesis is submitted, that at least some of Glatthorn's (1998: 186-8) commonly-asked examiner questions won’t arise:

1. Why did you choose that particular method? Why did you not instead use this other method?

2. Can you clarify for me how the particular method you chose relates directly to the problem you have chosen to study?

Examiners expect the rationale for the study to be clearly explicated - the early stages of writing are a good time to describe the thinking processes underpinning hypotheses or questions. Examiners will want to see

- rationale of general approach closely argued giving a reasoned case for rejecting other possible approaches;

- justification of research design presented, taking account of potential advantages and limitations; research techniques argued as theoretically and practically relevant to research problem;

- reasons given for rejection of possible alternatives, rationale provided for amendments to standard tests and procedures or for detailed design of innovative techniques' (adapted from Denicolo, 2002: 114-6)

Questions such as these can be used to guide feedback at all stages of students’ writing.

\section{Critical and analytical skills with the literature review}

In the early stages, the tsunami of literature to be covered seems overwhelming, and the scope, argument, methods, and questions of the project are likely to be still under negotiation. Nonetheless, students must learn to make sense of the literature as it relates to their own study, a task where writing, thinking and reflecting are closely intertwined. They must make meaningful notes to save themselves from having to circle back round. Ideally, these notes should construct a meta-narrative of the relevant research discourse: what were the monumental shifts; what points are contested; who sides with and against whom (Hart, 1998). Encouraging such questioning can feed into further writing that helps establish the student's own position within the discourse. Students need good supervisory support to cope with such mentally-challenging work (Carter, 2015). As they begin to find their 'voice', students also need to be encouraged to trust themselves as writers with full entitlement (Guerin, 2013). 
Writing up one's choices from the outset can help fit literature into the research project rather than being overwhelmed. A couple of Glatthorn's questions ask about research niche interest: 'When you reviewed the literature, why did you decide to review that particular area of study?' and 'You have reviewed the important literature, but I fail to see what use you make of your review. Can you clarify for me what you learned from the review of literature?'(Glatthorn, 1998: 187). Writing should preempt such questions.

Supervisors could set students the task of drafting questions relating to their research to ask of each piece of literature that they review. Such questions will come from the field of study - in literature studies, for example, my question were simply 'why do I like or dislike this?'. Often, though, questioning may consider sample size, methods, theory, funders, etc.; when doctoral students begin to feel comfortable about routinely interrogating what they are reading, they become increasingly enculturated to critical analysis and review. In this way, supervisors can subtly ensure that feedback on exploratory literature review drafts scaffolds students' learning on several levels. Textually preempting examiners' questions will also satisfy graduate committees during the provisional year review.

\section{What is the 'original contribution'?}

Assessing the significance of their original contribution can trouble students. The term 'originality' is vague, and often undefined and unquantified (Tinkler \& Jackson, 2004: 1178). Supervisors might like to share with students Tinkler and Jackson's range of what can be considered 'original' within their field, such as

- Research on new areas of study, data sets, questions, hypotheses, problems, links between topics/data sets and so on.

- Research processes

o New applications of established research tools - for instance, methods, instruments, conceptual tools, modes of analysis, procedures, theories, "practice"- - to different or new research topics.

o Significant refinement of established research tools or development of new research tools applied to established or new research topics.

o The application of new perspectives to research topics.

- Research outcomes (intentional or unintentional)

o New or substantially revised solutions, products, theories, knowledge, interpretations, approaches, ways of doing research (methods, instruments, conceptual tools, modes of analysis, procedures, applications of theory, "practice”).

o New syntheses of theory, knowledge or ways of doing research.

o The opening up of new or neglected areas for fundamental and significant further research. 
Such a list may assist students to identify their original contributions, and it's also useful to remind them to overtly state what is significant about their research in

- the introduction (areas of study, processes and outcomes);

- $\quad$ the methodology (processes);

- $\quad$ and outcomes (discussion and conclusion).

In many disciplines, when students adapt or modify theory or method, the explicit inclusion of words such as 'novel' or 'original' adds weight to persuade the examiner of the thesis's original contribution.

\section{Meeting 'internationally recognized standards'}

It is probably typical of New Zealand to spell out the need to be'recognized internationally': we are a small isolated country wanting to be taken seriously. However, all institutional criteria will expect the standard of doctoral research and writing to look professionally expert.

Increasingly, doctoral students opt for thesis by publication or publishing along the way. Even when writing a stand-alone thesis, students should aim for a voice that is authoritative and confident, and clearly expressed. Thesis prose should look publishable within an international peer reviewed journal. In a survey of 441 abstracts submitted for an international conference, Berkenkotter and Huckin (1998: p) identified the following factors that made peer-reviewers regard abstracts favorably:

1. clear definition of a problem or need;

2. novelty; and

3. ethos, in that 'high-rated abstracts typically project more of an insider persona', i.e competently use terminology and literature of the discipline.

Their first criterion is evident significance of the project (Ferris \& Hedgcock, 2014). Glatthorn (1998: 186-8) identifies typical oral examination questions, such as 'Why did you choose that particular problem? Why did you not study this other problem instead? What exactly were you trying to find out? I'm unclear about the meaning of your problem statement', questions that students should pre-empt in the written thesis. To encourage students to understand how to show an insider persona in writing, supervisors can ask them to find three articles by experts and highlight text (words, phrases and clauses) that convince them that these authors are discipline experts. Students can then emulate similar lexical, tonal, and rhetorical strategies in their own work once their attention is draw into the implicit workings of disciplinary discourses. 


\section{Making the 'quality and coherence of written expression' evidently 'satisfactory'}

This book suggests many approaches that supervisors can adopt to help research students reach their full potential as coherent and stylish writers. Doctoral students in particular need to learn to welcome the masochistic review process and become inured to the reiterative nature of good academic writing, the slog involved. The more people who give feedback at every stage of production, the more sets of collegial eyes looking for ambiguity, linguistic tangles and inaccuracies of any kind - helping with defence - the better. The ultimate question is whether 'the text of [the] thesis [is] sufficiently transparent with a perfectly clear intended meaning' (Boulter \& Denicolo, 2002: 43). Family and friends can helpfully signal when they lose track; writing that is reasonably clear to non-experts will usually satisfy examiners. Explaining a complex passage verbally to someone else, often shows students the need for sharper expression, or a few extra words, to strengthen the written document. As far as final quality is concerned, some students can afford professional proof reading, and some institutions provide assistance. Nevertheless, it's important to remind students that final responsibility is theirs alone.

\section{Finishing touches}

This section began with the idea of examination as the end-goal and closes in the same way. Awareness of examination practices and expectations that colours early writing should also guide final revisions. Before submission, encourage students to make a complete sweep of the entire document, checking that the joinery of their defensive bulwarks is sturdily and visibly in place. Trafford and Leshem (2002: 8-9) usefully provide a set of critical questions you might adapt to help your student critically review their own work:

- How did you relate the various stages of your research one to another?

- What is your contribution to knowledge?

- How important are your findings and to whom?

- How do you main conclusions link to the work of [other famous scholars]?

Allowing students to respond to this self-critique aided by a set of critical questions, is likely to alleviate pre-submission anxiety. It equips students with a practical workerly framework for self-reflection. Pre-submission pressure can add tension to the supervisory relationship; by emphasising the examination criteria, you can distance yourself, highlighting that is the academy itself demanding high standards.

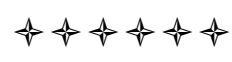




\section{What examiners value in a $\mathbf{P h D}$}

Sue Starfield (University of New South Wales, Australia)

Students and supervisors are often surprised when I talk to them about the research into what examiners look for in a PhD thesis. Almost apologetically, I'll explain that it's an area of growing interest. John Swales, the well-known applied linguist, coined the phrase 'occluded genres' (Swales, 1996) to describe genres that are not publicly or easily available. The PhD examination process and the examiners' reports that make our hearts sink or soar are typical examples of hidden or occluded genres. Fortunately, we now have some research that shines a light into examiners' preferences. This information is particularly important for students and their supervisors in countries like Australia where there is typically no oral defence or viva and examination is based solely on the written thesis. There is, however, much that supervisors everywhere can take from the research into examiners' expectations to inform the guidance they provide to their students from the earliest stages of the thesis journey until submission.

As one of the experienced PhD examiners interviewed in Mullins and Kiley's (2002: 386) well-known study explained: 'A PhD is a stepping stone into a research career. All you need to do is to demonstrate your capacity for independent, critical thinking. That's all you need to do. A PhD is three years of solid work, not a Nobel Prize'. A quick Google search of Nobel Prize winners suggests there is some truth in this-many are quite elderly by the time the earn the coveted award and it seems unlikely that they would have received it for their doctoral scholarship — although it may well have started them on the path to future glory ${ }^{1}$. So the key message here is 'get it done' - do it well but see the $\mathrm{PhD}$ as a time-limited stage in your career development.

One of the key messages that can be distilled from the research is that first impressions count. Experienced examiners decide very early on whether the assessment of a thesis is likely to be 'hard work' or 'an enjoyable read' and their initial impression of the quality of the thesis is usually formed by the end of the second or third chapter - often by the end of the literature review. 'It is unusual that if someone does a poor job of the literature review that they will suddenly improve’ said one experienced examiner (Mullins \& Kiley, 2002: 377). Supervisors do need to make it clear to their students that chapters like the literature review that are often drafted early in the thesis process need to be kept updated and revised, often substantially, prior to submission.

\footnotetext{
${ }^{1}$ John Nash, who died tragically in 2015, was awarded a Nobel Prize with two other economists in 1994, based on work in his 1950, 28-page PhD dissertation.
} 
We would all like our students' theses to be in the enjoyable read category. What can we do to get it there? Here are some of the things that a study of examiners' reports (Johnston, 1997: 340-341) tells us:

- Examiners approach reading a thesis with an air of expectation and even enthusiasm, but this disappears if the thesis is not reader-friendly (my emphasis).

- General impressions and overall presentation of the thesis are particularly important.

- The reader needs to be assisted through the use of summaries, logical sequencing, signposts and removal of excessive repetition.

- All readers require assistance to understand the work.

- They feel distracted and irritated by poorly presented work.

- They appreciate well-written, interesting and logically presented arguments.

Mullins and Kiley (2002: 378) note that 'sloppiness' is one of the most commonly-used words to indicate a negative response to a thesis. Sloppy presentation suggests to the examiner that the research might well be sloppy and they read the thesis with a more critical eye. One of the examiners interviewed by Mullins and Kiley noted just how significant a role the student's perceived 'lack of care' can play in the examination:

I give my students strong advice on how not ‘flip' an examiner from 'reasonable' to 'unreasonable' by having irritating things in the thesis such as typos and other careless textual mistakes that indicate lack of attention to detail. Once flipped (and I am aware of this happening), I am irritated and I have to work very hard at overcoming this irritation and not letting it influence my view of this thesis, although this is not easy' (in Mullins \& Kiley: 378).

Just the other day, I was chatting to a PhD student who was about to submit his $\mathrm{PhD}$ thesis for examination and was just waiting for the supervisor's final sign off. I ran through a couple of the key things that need to be done before final submission. Semi-jokingly I said, 'Have you checked your Table of Contents'. The student visibly paled: 'Table of Contents? No one's mentioned that.' As I had fairly recently examined a thesis in which there was no Table of Contents, I knew just how that 'flipped' me from well-disposed to slightly more suspicious examiner. A fellow experienced examiner's account of how he approaches examining a thesis illustrates the importance of the Table of Contents in the assessment process:

First of all I look at the structure to see if there is a logical progression. I look at the table of contents just to see whether it makes sense from that point of view. How much space is devoted to a certain section. You know roughly what should be there. I guess I try and find what is the contribution of research and hopefully there is a section there which outlines the contributions of the research and then once you know what they claim what they have done other than the results that they have achieved then you can verify it is their actual work. (Kiley \& Mullins, 2004: 130) 
Is it part of the supervisor's role to remind a student of the necessity for a Table of Contents? I certainly believe we should encourage our students to look at recently submitted theses in our Schools and Departments that have been well received by the examiners. These theses can provide students with a sense of what is expected of them. In addition there are a number of online repositories which host completed PhD theses and we should encourage our students to consult sites such as Trove http://trove.nla.gov.au/ or Proquest Theses and Dissertations http://www.proquest.com/products-services/pqdtglobal.html, to which many universities subscribe.

As Johnston's (1997: 345) study argued, examiners do not approach a thesis as 'experts in the field who will judge accordingly’ but 'just like a readers of any new piece of writing'. A reader-friendly thesis is the outcome of multiple drafts; it is vitally important that supervisors communicate this message clearly to students from early on. Feedback from readers including, but not limited to, the supervisors is essential. Supervisors should encourage their students to join writing groups and other writing support initiatives where possible. In the final stages, I like to recommend that a proof-reader or at least a reasonably literate friend read through the entire thesis prior to submission. It has to be someone other than the author who, towards the end, will not see typos, grammatical errors, repetitions and illogicalities. Some may need an editor for more help with grammar and language. Whichever the route chosen, redrafting takes time. Count back from the submission date and build in the time needed for the final polishing - it always takes longer than anticipated. But as the research shows, the effort put in to craft a reader-friendly text will be worth it. The research points to numerous negative comments focussing on the need for proofreading that seem to impact on the overall assessment such as, 'I lost count of the number of times that singular nouns were referred to in the plural-an irritant that should not have survived proofreading. This added to the overall impression that the work was rushed and not subjected to adequate preliminary review' (Johnston, 1997: 339). Chapter 11, 'Before you submit', in How to write a better thesis (Evans, Gruba \& Zobel, 2011) has a great checklist of all the many things that need to be done to polish the final draft of the thesis. I encourage all the students I talk to at workshops and seminars to print it out and use it.

Kiley and Mullins (2004) also asked examiners how they went about reading the thesis. Rather than sitting down and reading it from cover to cover as one might a novel, the majority of the examiners surveyed begin with the abstract, introduction and conclusion and of course the references. At a later stage, when they have a good chunk of time, they will read the thesis through in a more linear way. Again, first impressions are important: a clear abstract with no typos; a well-written introduction that has not been written in haste a week or two before submission and a thought-through conclusion that clearly shows how the questions raised in the introduction have been addressed go some way to shaping that positive first impression. And of course, as I mentioned above, an up to date reference list including all articles, chapters and books referred to in the thesis helps too. Contrary to the advice on 
many thesis writing websites and blogs, I advise my students and the supervisors I talk to of the importance of drafting the introduction early in the writing process. While there may be some truth in the view that the introduction can only be written once the thesis is complete, my view is that having a working draft that can be regularly updated helps student and supervisor keep track of the thesis's evolution.

From another negative comment, we learn that a high quality literature review should do more than 'review' a body of literature. It should be structured as an argument for why this research needs to be done: 'clearly the author can examine and review a complex body of literature. However, a literature review must carry a major part of the argument in the thesis, the argument that convinces the reader of the need to investigate the to-be-specified research questions' (Holbrook et al., 2008: 351). This is a perspective that many students fail to grasp and that supervisors can guide them in developing. As another examiner wrote: 'literature reviews whilst exploring every facet of the related research should pivot around the central argument of the thesis and flow the reader through the justification for the research (351).

Examiners' reports also provide an insight into the examiner's expectations about other aspects of what constitutes a 'good' thesis. For example, Holbrook et al. (2008: 350) point to expectations the literature review will be linked with the thesis's findings, a point that might otherwise remain implicit. A negative comment thus stated: 'I was a bit amazed that relatively few references were given in the discussion and conclusion sections, which are typically the parts of the work in which the results are compared to the earlier work' whereas a more positive one commended the candidate for, 'a very good effort ... made at tying the results back into the existing literature.' I have found that this dimension of the discussion section - that it is that part of the thesis in which the student begins to show their contribution through referring to the previous literature-is often not apparent to students. Here again the supervisor can make sure the student is aware of this function of the discussion chapters.

The number of students who actually fail the PhD examination is extremely small. Many will, however, be required to do revisions, with Holbrook et al. (2014) revealing that formative comments constitute a large proportion of the examiners' reports they analysed. In the words of one of the examiners interviewed by Mullins and Kiley (2002: 383), doctoral assessment provides 'an opportunity for the students to be able to incorporate comments so that it [the thesis] sits on the library shelf and glows more brightly'. In conclusion, it is worth emphasising the reciprocal relationship that exists between examining and supervising: becoming an examiner of doctoral theses can help us become better supervisors as we, too, are pushed to articulate what we expect in a 'good enough' thesis.

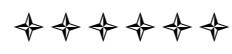


[1] John Nash, who died tragically in 2015, was awarded a Nobel Prize with two other economists in 1994, based on work in his 1950, 28-page PhD dissertation.

\section{Keeping the examiner happy}

- Draw attention to end goal ('examiners' expectations') from outset:

o encourage students to conduct self-audit: what skills/concepts/ behaviours are required to achieve 'doctorateness' within field? Which do they need to work on? How will they do this?

o acknowledge writing process and production, as well as content-related issues.

- Anticipate—and pre-empt—potential questions:

o encourage students to keep running record of all process-related decisions (why this setting/, why this method [and not another]? how data analysed? etc).

- Encourage students to take up every opportunity to explain study to different audiences:

o informal writing group discussions;

o publications in related journals;

o Three Minute Thesis (3MT) competition;

o seminar and conference presentations.

- Empower students to present themselves to best advantage:

o encourage ‘self-talk' (“why do I like/dislike this article?”) to help students justify thinking processes within their writing;

o encourage them to examine published theses for exemplars of what to include (and where);

o stress importance of tying whole thesis together (cohesiveness between 'Intro and Conclusion', research questions answered; signposts \& linkages between sections, formatting consistencies, etc)

- Provide feedback in good time, allowing months (not weeks) for final polishing and proofreading.

- Foreshadow likelihood of further revisions (in light of examiners' comments). 